\title{
The problem of uveitis in Bendel State of Nigeria: experience in Benin City
}

\author{
J. O. AYANRU \\ From the University of Benin Teaching Hospital, Nigeria
}

SUMMARY A review of 1987 patients with uveitis seen over an 11-year period in Bendel State of Nigeria has been undertaken; $56 \%$ of cases had a posterior/mid-peripheral uveitis, $15 \cdot 1 \%$ a panuveitis, $21.5 \%$ an anterior uveitis. Acute anterior uveitis with classical symptoms was rarely seen. Its comparative rarity is presumably due to the absence of HL-A27 in Africans and altered immunological states from malaria and parasitic infections.

Identified aetiological factors in anterior uveitis were leprosy (1 patient), tuberculosis (1 patient), herpes zoster (16 patients), and onchocerciasis (3 patients). The great majority of cases of posterior uveitis were of presumed toxoplasmic origin. Further studies are needed to demonstrate its mode of transmission in a population in which toxoplasmosis is endemic. Forest onchocerciasis is not a major cause of uveitis in southern Nigeria in the same way as savanna onchocerciasis is in northern Nigeria. Syphilis seems to play no part in the causation of uveitis in southern Nigeria. Better diagnostic facilities are required to determine the role of sarcoidosis and other possible causative factors. Uveitis is a major cause of blindness in Nigeria.

Uveitis is a major cause of blindness in Nigeria (Olurin, 1973; Ayanru, 1974). It occurs mainly as a posterior uveitis or a panuveitis, anterior uveitis being relatively rare. This account reviews 1987 patients with uveitis seen over a period of 11 years, 1965-76, at the eye clinic of the Specialist Hospital, Benin City, Bendel State of Nigeria.

\section{Materials and methods}

The eye clinic of the Specialist Hospital, Benin City, was the only eye unit serving a population of $2 \frac{1}{2}$ million people of the Bendel State of Nigeria during the period 1965-73. For varying periods it had one and sometimes two ophthalmologists only. In 1973 another eye clinic, at the University of Benin Teaching Hospital, was started. The Specialist Hospital eye clinic nevertheless remained the first port of call for patients with eye disease. Patients were also seen from neighbouring States of Nigeria, accounting for $1.5 \%$ of the 33634 new ophthalmic patients who attended the clinic during the period under review. 1987 patients presented with uveitis $(5.87 \%$ of total). Those who had endophthalmitis and traumatic uveitis have been excluded. Among the patients seen were soldiers with ocular injuries during the Nigerian

Address for reprints: Dr J. O. Ayanru, University of Benin Teaching Hospital, PMB 1111, Benin City, Nigeria civil war, when Benin City was a major base for the treatment of wounded soldiers.

Clinical examination was by ophthalmoscopy and biomicroscopy with a Haag Streit slit lamp before and after dilatation of the pupil with mydriatics.

All patients with uveitis had visual acuity tests, blood tests including a full blood count, erythrocyte sedimentation rate, Kahn or Wasserman test for syphilis, and a skin-snip examination for onchocerciasis. Over $65 \%$ of patients had a chest $x$-ray examination. Radiological investigations of sacroiliac joints, teeth, and sinuses were carried out in cases of anterior uveitis on 385 patients only. A Heaf test or Mantoux was done in cases presenting with a 'granulomatous uveitis'. The particular test done depended on which of the antigens was available at any one time. The Kveim, histoplasmin, toxoplasmin antigens and the Sabin-Feldman methylene blue dye test and uveal antigen are not available locally, nor are they readily available commercially elsewhere.

The mainstay of treatment was steroids-topical, systemic, or depot-and atropine. This regimen was combined with pyrimethamine in suspected cases of toxoplasmosis or diethylcarbamazine in proved cases of onchocerciasis. Occasionally the latter drug was used as a therapeutic test in cases in which skin snips were negative for onchocerciasis. 
Results

The most prominent symptoms were visual blurring in 1846 patients $(92.9 \%)$, redness in $150(7.5 \%)$, light intolerance in $79(4.0 \%) .1256$ patients $(63.2 \%)$ on first reporting had a visual acuity of $6 / 60$ Snellen or less, suggesting delay in reporting or inflammation at the posterior pole in and around the macula or considerable vitreous haze. In other cases it was a burnt out lesion at the macula with amblyopia and squint or secondary cataract and other complications that brought the patient to hospital.

In acute cases, in spite of evidence of intense anterior segment activity-keratitic precipitates flare-pain, ache, and photophobia were often not very prominent symptoms.

The average duration of symptoms before reporting was 1 to 2 weeks in cases of acute anterior uveitis. In posterior uveitis the interval varied with the literacy of the patients. Literate patients reported within 2 weeks. Other groups or those living some distance away from the clinic reported on the average at 3 months or when vision was completely lost.

The sites of the inflammation are as shown in Table 1. It must be admitted that in a large proportion of cases it was impossible to determine the site of the inflammation at the first visit on account of severe vitreous haze. Such cases were subsequently classified when inflammation had subsided. Cases of iridocyclitis following trauma were excluded in the group of anterior uveitis.

The male:female sex ratio was $2: 1$. There is, however, a high preponderance of males over females in all non-gynaecological clinics. No particular socioeconomic group was prone to developing uveitis. The peak age was 19 to 29 years (Fig. 1). One patient had a recurrence during pregnancy, while 2 had a first attack during pregnancy.

In spite of treatment 334 patients were blind (visual acuity of counting figures at $1 \mathrm{~m}$ and less) in one eye from a chronic posterior uveitis, 69 from a chronic anterior uveitis. Fifty patients and 4 patients

Table 1 Sites of inflammation

\begin{tabular}{lll}
\hline No. of patients & Site of lesion & $\%$ of total \\
\hline 812 & Posterior choroidoretinal lesion & $40 \cdot 9$ \\
300 & Mid-peripheral & $15 \cdot 1$ \\
300 & Panuveitis & $15 \cdot 1$ \\
429 & Anterior uveitis & $21 \cdot 6$ \\
146 & Unstated & $7 \cdot 3$ \\
\hline 1987 & & $100 \cdot 0 \%$ \\
\hline
\end{tabular}

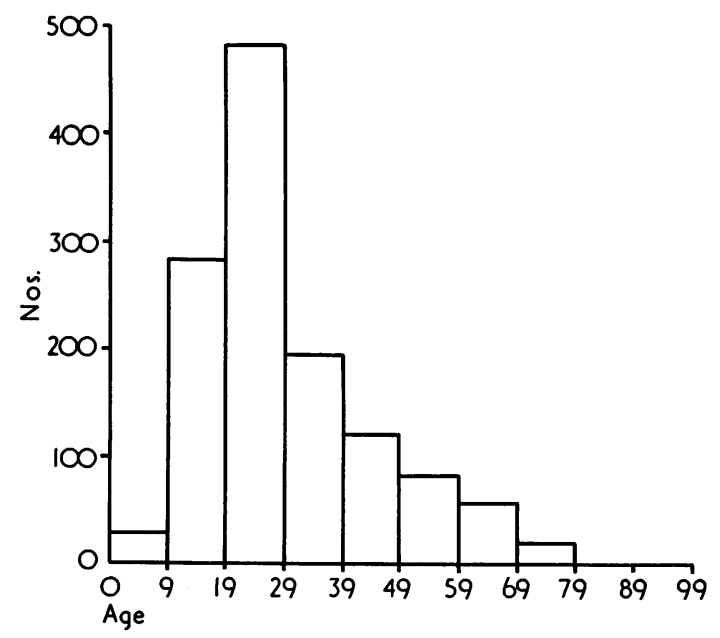

Fig. 1 Distribution of uveitis cases by age

were blind in both eyes from chronic posterior and chronic anterior uveitis, respectively.

There were no cases with positive serology for syphilis, nor was there radiological evidence of pulmonary tuberculosis in any of the patients. No cases of sarcoidosis were diagnosed. Positive skin snips for onchocerciasis (Onchocerca volvulus) were obtained in 6 patients, although in only 3 was ocular involvement diagnoser.

\section{Discussion}

The incidence of uveitis in the population studied is $5.87 \%$. Uveitis causes the attendance of $8 \%$ of all new attendances at the University College Hospital, Ibadan (Olurin, 1973), the higher percentage in Ibadan probably reflecting the greater selectivity in a teaching hospital.

Uveitis is a major cause of blindness in one or both eyes in Nigeria (Olurin, 1973; Ayanru, 1974). The great majority of cases are of the posterior type $(71 \cdot 1 \%)$, acute anterior uveitis being relatively uncommon. In this series it accounted for $21.5 \%$ of cases.

The commonest and often the only presenting symptom is visual blurring. Pain, redness, watering, and photophobia are comparatively rare even in the presence of intense anterior chamber activity. The notable exception is traumatic uveitis, in which these symptoms may predominate. It is therefore not surprising that it is the literate patients-students, civil servants, literate housewives-that usually report early.

The investigation and hence the diagnosis of uveitis poses specific problems in this environment. Diagnostic facilities are limited and the specific anti- 
gens are not available. In view of the comparative rarity of acute anterior uveitis and the virtual absence of ankylosing spondylitis, $x$-rays of the sacroiliac joints are now seldom undertaken (Schlaegel, 1969). The Heaf or Mantoux tests, chest $x$-rays, skin snips for onchocerciasis, blood examination for eosinophilia, erythrocyte sedimentation rate, and serological tests for syphilis have been routine. The presence of ova of Ascaris lumbricoides or Ankylostoma duodenale in the stools of a patient with uveitis does not mean they cause the disease in this largely farming community with poor sanitation. Reliance has therefore been placed on the clinical picture (Woods, 1961), with emphasis on the location of the lesions (Perkins, 1961; Hogan et al., 1959; Spalter and Len, 1966), and a therapeutic trial.

Thus it is not surprising that the cause of the disease often defies elucidation, although ecological and racial factors and knowledge of the pattern of diseases have greatly influenced diagnosis and hence possible treatment. But difficulty in detecting the cause of uveitis is not peculiar to this environment (Duke-Elder and Perkins, 1966; Schlaegel, 1969; Aronson et al., 1968; Perkins, 1968; Saari et al., 1975).

Toxoplasmosis is probably the single greatest factor in the causation of uveitis in the forest areas of Nigeria, in which Bendel State is situated. The fact that the clinical picture is one of a posterior uveitis, often recurrent, and near the macula, disc, or midperipheral in about $70 \%$ of cases (Ayanru, 1974), is highly suggestive. Chesterton and Perkins (1967) found a high percentage of presumed ocular toxoplasmosis in West African immigrants in London and a positive dye test in $89 \%$ of West African patients even without uveitis. The lesions were more frequently anterior to the equator than those seen in the indigenous population. Serological studies in the Delta area of Nigeria (Ludlam, 1965) and at Ibadan (Olurin et al., 1972) confirm the endemicity of toxoplasmosis in Nigeria. The highest incidence in this series was in the second and third decades of life, 'which coincides with the period of greatest $\mathrm{T}$ cell activity as the body suddenly becomes aware of and mounts up a severe reaction against a previously tolerated antigen' (Desmonts and Couvreur, 1974). The patients who had a presumed toxoplasmic chorioretinitis in pregnancy may well have developed the lesions as a result of altered immunological competence, since most ocular toxoplasmosis is congenital (Perkins, 1973), and the infection may have lain dormant until pregnancy. None of the babies born to all three mothers had clinical evidence of disease. Depressed cellular immunity in pregnancy has been attributed to a serum factor (St. Hill et al., 1973). Recurrences of ocular toxoplasmosis are more frequent during pregnancy.

Onchocercal uveitis-an iridocyclitis and peripheral chorioretinitis-and the degenerative posterior lesions of onchocerciasis seen in the savanna areas endemic for onchocerciasis (Hissette, 1932; Bryant, 1935; Ridley, 1945; Budden, 1955; Rodger, 1960; Neumann and Gunders, 1973; Bird et al., 1976) have not been seen in this State, which lies in the rain forest area of Nigeria. Distinct epidemiological differences exist between forest and savanna onchocerciasis (Budden, 1963). In only 3 patients has onchocercal kerato-uveitis been proved here.

Syphilitic uveitis is not uncommon in northern Nigeria (Rodger, 1960). Syphilis is, however, rare in southern Nigeria, where yaws was endemic and shows cross-immunity against syphilis. None of the patients in this series showed serological evidence of syphiiis.

Although only one patient with lepromatous leprosy and anterior uveitis was seen, examination of 179 patients at the Ossiomo Leper Settlement in the State showed that, of the 25 patients whose blindness was attributable to leprosy, 9 (36\%) had iridocylitis. Eight of the 9 patients suffered from lepromatous leprosy and the ninth borderline lepromatous leprosy (Ayanru, 1975).

One patient with a granulomatous uveitis which failed to respond to steroid therapy was ultimately controlled with antituberculous drugs on the basis of a grade III positive Heaf test and the presence of mutton-fat keratitic precipitates. No primary focus was detected. Tuberculous uveitis is known to occur more in people with old or burnt-out tuberculosis than in those with active disease (Duke-Elder and Perkins, 1966).

Ogunlesi and Rankin (1961) and Femi-Pearce and Odunjo (1973) described cases of sarcoidosis in Nigerians in which uveitis was a feature. Although various aspects of African histoplasmosis have been documented (Clarke et al., 1953; Duncan, 1958; Lucas, 1970) and reports of human brucellosis in southern Nigeria have appeared (Alausa and Awoseyi, 1976), there are no reports of ocular involvement. Sixteen cases of uveitis associated with herpes zoster ophthalmicus have been recorded. There is a relative infrequency of herpes zoster ophthalmicus affections.

Anterior uveitis, particularly acute, is commoner in Caucasian patients in London (Perkins, 1961, 1968), anterior uveitis accounting for 12 cases out of a population of 100000 per year as compared to only 3 cases of posterior uveitis in the United States (Darrel et al., 1962). The comparative rarity among Nigerian patients of acute non-granulomatous uveitis typically associated with various rheumatic diseases, classical ankylosing spondilitis, Reiter's 
disease, and Yersinia arthritis shown to be associated with an increased incidence of the histocompatibility antigen HLA-27 in Caucasian patients (Brewerton et al., 1973; Ehlers et al., 1974; Mapstone and Woodrow, 1975; Caffrey and James, 1973; Schlostein et al., 1973; Aho et al., 1973) can now be partly explained by the characteristic absence of the genetic marker HLA-27 among Africans and its presence among only $4 \%$ of Black Americans (O'Connor, 1974). These various conditions associated with acute anterior non-granulomatous uveitis are very rare in Nigeria and many parts of tropical Africa (Payet et al., 1966; Greenwood, 1968). Greenwood (1968) has suggested that in Nigeria and other African countries the relative rarity of connective tissue and autoimmune diseases may be partly explained by the altered immunological state of Africans through malaria and various parasitic infections in the region. Huldt et al (1973) and Strickland et al (1973) have reported immunosuppression in mice infected with toxoplasma organisms, and there are indications that toxoplasmosis, like viral hepatitis, can cause immunosuppression (O'Connor, 1974). Both toxoplasmosis and viral hepatitis are endemic in Nigeria (Ludlam, 1965; Edington and Gilles, 1969; Olurin et al., 1972).

Iridocyclitis due to cerebrospinal meningitis (Budden, 1952), which latter disease often rages in epidemic form in northern Nigeria, is rarely seen in southern Nigeria. No cases were recorded here. Gonorrhoea is common and on the increase. Its role in the causation of uveitis in Nigeria is undetermined.

Unlike the experience of Freedman (1973) among South African Bantu children no case of sympathetic ophthalmitis was recorded in this series in spite of the high incidence of perforating ocular injuries and the usual habit of reporting late in hospital. Several factors other than racial have a part to play in the genesis of this condition (Mann, 1961). No patients with heterochromic cyclitis or the VogtKoyanagi-Harada syndrome have been seen, nor have cases of uveitis induced by dexamethasone sodium sulphate been encountered (Martins et al., 1974).

In the absence of a precise ascertainment of the cause in most of these cases the mainstay of treatment has been steroids-depot, topical, or systemic -with mydriatics. Diethylcarbamazine tablets and topical hetrazan have been used in the isolated cases of onchocerciasis as topical hetrazan is of proved value (Ben-Sira et al., 1970).

Pyrimethamine and/or sulphadiazine were not given in addition as a routine in suspected cases of toxoplasmosis because no difference has so far been found here in the recurrence rate or healing of lesions in patients so treated. The dangers of giving steroids without antimicrobial therapy have been highlighted (Editorial, 1976), but the persistent leucopenia seen in the few patients so treated, particularly in an environment where patients cannot be relied upon to return for a check-up once their ocular disability seems less, has influenced this mode of treatment. Perhaps this regimen can also be justified on the basis of O'Connor's report (1974) that both pyrimethamine and sulphonamide produced disappointing or unreliable results in human ocular toxoplasmosis, especially when the lesions were large or of long duration. They were useful in cases of acute small lesions. Most of these patients reported late in hospital. Neither clindamycin nor BCG have been used in the treatment of our cases of presumed ocular toxoplasmosis (Cahill, 1974). No cases of uveitis have been sufficiently intractable to warrant the use of immunosuppressive agents (Martenet, 1972) or cryotherapy (Aaberg et al., 1973).

I thank the following who have made the project possible: Dr (Mrs) Savova and Dr Idehen, who consulted with me at various times and whose records have been most useful. My thanks also go to the records clerk and nursing staff of the eye clinic of the Specialist Hospital for their full co-operation, not least to Mrs B. Jaboro for patient secretarial services.

\section{References}

Aaberg, T. M., Cesarz, T. J., and Flickinger, R. R. (1973). Treatment of peripheral uveoretinitis by cyrotherapy. American Journal of Ophthalmology, 75, 685-688.

Aho, K., Ahvonen, P., Lassus, A., Sievers, K., and Tilikainen, A. (1973). HL-A antigen 27 and reactive arthritis. Lancet, 2, 157.

Alausa, D., and Awoseyi, A. (1976). Brucellosis: The situation in Western Nigeria. Tropical and Geographical Medicine, 28, 54-59.

Aronson, S. B., Gamble, C. N., Goodner, E. K., and O'Connor, G. R. (1968). Clinical Methods in Uveitis, 'The testing of microbial allergies in uveitis', pp. 177-182. C. V. Mosby: Saint Louis.

Ayanru, J. O. (1974). Blindness in the Mid-Western State of Nigeria. Tropical and Geographical Medicine, 26, 325-332.

Ayanru, J. O. (1975). Ocular leprosy in Nigeria. Nigeria Medical Journal, 5, 258-262.

Ben-Sira, I., Aviel, E., Lazar, M., Lieberman, T. W., and Leopold, I. H. (1970). Topical hetrazan in the treatment of ocular onchocerciasis. American Journal of Ophthalmology, 70, 741-43.

Bird, A. C., Anderson, J., and Fuglsang, H. (1976): Morphology of posterior segment lesions of the eye in patients with onchocerciasis. British Journal of Ophthalmology, 60, 2-20.

Brewerton, D. A., Nicholls, A., Caffrey, M., Walters, O., and James, D. C. O. (1973). Acute anterior uveitis and HLA27. Lancet, 2, 994-6.

Bryant, J. (1935). Endemic retina-choroiditis in the AngloEgyptian Sudan and the possible relationship to Oncho- 
cerca volvulus. Transactions of the Royal Society of Tropical Medicine and Hygiene, 28, 523-533.

Budden, F. H. (1952). Blindness in northern Nigeria. British Medical Journal, 1, 1248.

Budden, F. H. (1955). Incidence of human infection with onchocercissis in different communities in relation to the incidence and type of the ocular lesions. British Journal of Ophthalmology, 39, 321-332.

Budden, F. H. (1963). Comparative study of ocular onchocerciasis in savannah and rain forest. Transactions of the Royal Society of Tropical Medicine and Hygiene, 57, 64-70.

Caffrey, M. F., and James, D. C. (1973). Human lymphocyte antigen association in ankylosing spondylitis. Nature, 242, 121.

Cahill, K. M. (1974). Symposium on toxoplasmosis. Bulletin of the New York Academy of Medicine, 50, 107-239.

Chesterton, J. R., and Perkins, E. S. (1967): Ocular toxoplasmosis among immigrants in London. British Journal of Ophthalmology, 51, 617-621.

Clarke, G. H. V., Walker, J., and Winston, R. M. (1953). African histoplasmosis. Journal of Tropical Medicine and Hygiene, 56, 277-280.

Darrel, R. W., Kurland, L., and Wagenes, H. P. (1962). Epidemiology of uveitis: incidence and prevalence in a small urban community. Archives of Ophthalmology, 68, 502-514.

Desmonts, G., and Convreur, J. (1974). L'isolement du parasite dans la toxoplasmose congenitale: interêt pratique et théoretique. Archives Françaises de pédiatrie, 31, 157-166.

Duke-Elder, S., and Perkins, E. S. (1966). System of Ophthalmology, 'Diseases of the Uveal Tract,' Vol. IX, pp. 41, 249. Henry Kimpton: London.

Duncan, J. T. (1958). Tropical African toxoplasmosis. Transactions of the Royal Society of Tropical Medicine and Hygiene, 52, 468-474.

Edington, G. M., and Gillies, H. M. (1969). Pathology in the Tropics, p. 482. Edward Arnold: London.

Ehlers, N., Kissmeyer-Nielsen, F., Kjerbye, K. E., and Lamm, L. U. (1974). HL-A27 in acute and chronic uveitis. Lancet, 1, 99.

Editorial (1976). Dangers of steroid treatment in toxoplasmosis. Archives of Ophthalmology, 94, 213.

Femi-Pearce, D., and Odunjo, E. O. (1973). Sarcoidosis in the Nigerian. Tropical and Geographical Medicine, 25, 130-138.

Freedman, J. (1973). Anterior uveitis in Bantu children. British Journal of Ophthalmology, 57, 355-358.

Greenwood, B. M. (1968). Autoimmune disease and parasitic infections in Nigerians. Lancet, 2, 380-382.

Hissette, J. (1932). Mémoire sur l'Onchocerca volvulus 'Leuckart' et ses manifestations oculaires sur Congo Belge. Annales de la Société Belge de Médecine Tropicale, 12, 433.

Hogan, M. J., Kimura, S. J., and Thygeson, P. (1959). Signs and symptoms of uveitis: anterior uveitis. American Journal of Ophthalmology, 47, 155-176.

Huldt, G., Gard, S., and Olovson, S. G. (1973). Effect of Toxoplasma gondii on mouse thymus. Nature, 244, 301303.

Lucas, A. O. (1970). Cutaneous manifestations of African histoplasmosis. British Journal of Dermatology, 82, 435447.

Ludlam, G. B. (1965): Toxoplasma antibodies in inhabitants of the Niger Delta. Transactions of the Royal Society of Tropical Medicine and Hygiene, 59, 83-86.

Mapstone, R., and Woodrow, J. C. (1975). HL-A27 and acute anterior uveitis. British Journal of Ophthalmology, 59, 270-5.

Mann, I. (1961). Culture, Race, Climate and Eye Disease, p. 554. Charles C Thomas; Springfield, Illinois.

Martins, J. C., Wilensky, J. T., Assef, C. F., Obstharim, S. A., and Buerk, K. M. (1974). Corticosteroid induced uveitis. American Journal of Ophthalmology, 77, 433-437.

Martenet, A. C. (1972). Indications de I'immunosupression par cytostatiques en ophthalmologie. Ophthalmologica, 165, 176-183.

Neumann, E., and Gunders, A. E. (1973). Pathogenesis of the posterior segment lesion of ocular onchocerciasis. American Journal of Ophthalmology, 75, 82-89.

O'Connor, G. R. (1974). The uvea. Archives of Ophthalmo$\log y, 91,401-415$.

Ogunlesi, T. O., and Rankin, T. B. (1961). Sarcoidosis in West Africa. Journal of Tropical Medicine and Hygiene, 64, 318-320.

Olurin, O., Fleck, D. G., and Osuntokun, B. (1972). Toxoplasmosis and chorioretinitis in Nigeria. Tropical and Geographical Medicine, 24, 240-245.

Olurin, O. (1973). Causes of blindness in Nigeria. West African Medical Journal, 22, 97-107.

Payet, M., Pene, P., and Sankale, M. (1966). Cliniques Africaines, p. 14. Paris.

Perkins, E. S. (1961). Analysis of 1718 cases of uveitis: Quoted by Duke-Elder, S., and Perkins, E. S. (1966). System of Ophthalmology, 'Diseases of the Uveal Tract,' Vol. IX, p. 419.

Perkins, E. S. (1968). Uveitis survey at the Institute of Opthalmology, in Clinical Methods in Uveitis, ed. Aronson et al. C. V. Mosby: St. Louis.

Perkins, E. S. (1973). Ocular toxoplasmosis. British Journal of Ophthalmology, 57, 1-17.

Ridley, H. (1945). Ocular onchocerciasis. British Journal of Ophthalmology Monograph Supplement, 10.

Rodger, F. C. (1960). The pathogenesis and pathology of ocular onchocerciasis, IV. American Journal of Ophthalmology, 49, 560-592.

Saari, M., Miettinen, R., and Alanko, H. (1975). Uveitis report of a 10-years survey in Northern Finland. Canadian Journal of Ophthalmology, 10, 356-360.

Schlaegel, Jr. (1969). Essentials of Uveitis, pp. 14-15. Churchill: London.

Schlosstein, L., Terasaki, P. I., Bluetone, R., and Pearson, C. M. (1973). High association of HL-A antigen W27 with ankylosing spondylitis. New England Journal of Medicine, 288, 704-706.

Spalter, H. F., and Len, P. J. (1966). Antigenic differences between anterior and posterior segments of the bovine uveal tract. Archives of Ophthalmology, 75, 526-34.

Strickland, G. T., Pettitt, L. E., and Voller, A. (1973). Immunosuppression in mice infected with Toxoplasma gondii. American Journal of Tropical Medicine and Hygiene, 22, 452-455.

St. Hill, C. A., Finn, R., and Denye, V. (1973). Depression of cellular immunity in pregnancy due to a serum factor. British Medical Journal, 3, 513-514.

Woods, A. C. (1961). Endogenous Inflammations of the Uveal Tract, p. 45. Wilkins and Wilkins: Baltimore. 